\title{
Retrospective review of the epidemiology of epilepsy in special schools for children with cerebral palsy, learning difficulties, and language and communication difficulties
}

\author{
Danielle Samar Peet*
}

\begin{abstract}
:
Purpose of the study: To determine in children the proportion and characteristics of epilepsy associated with cerebral palsy, learning difficulties and language and communication difficulties in a specific population of two special schools.

Basic procedures: Retrospective review of case notes for 142 children in two special schools (school $A$ and school B) in Newcastle, UK

Main findings: School A had more children with learning difficulties $\left(X^{2}=32.41, p<0.01\right)$ and active epilepsy $\left(X^{2}=3.03, p=0.08\right)$ than school $B$. There were more children with cerebral palsy $\left(X^{2}=9.56, p<0.01\right)$ and language and communication problems $\left(X^{2}=4.25, p=0.03\right)$ at school $B$ compared to school A. Active epilepsy is significantly more common in children with cerebral palsy $\left(X^{2}=7.58, p=0.01\right)$. All children with cerebral palsy and learning difficulties had epilepsy $(n=6)$. Although not statistically significant, those children who developed epilepsy within the first 24 hours of life were more likely to have cerebral palsy than those who developed epilepsy later in life $\left(\mathrm{X}^{2}=3.10, \mathrm{p}=\mathbf{0 . 0 8}\right)$. Those children with cerebral palsy tended to have a lower birth weight $(t=3.15, p<0.01)$ and a shorter gestation $(t=3.17, p<0.01)$ than children without cerebral palsy.

Principal conclusions: The data supports evidence from previous studies, demonstrating that epilepsy commonly accompanies cerebral palsy, thus complicating this difficult chronic condition. We show an association between both low birth weight and gestational age, and early age of onset of seizures, in children with cerebral palsy. This illustrates the importance, in these children, of past medical history from birth to determine risk factors for epilepsy later in life.
\end{abstract}

Key words: cerebral palsy, epilepsy, learning difficulties, language and communication difficulties

\section{INTRODUCTION}

Cerebral palsy (CP) is a chronic disorder of movement and posture caused by a non-progressive

* To whom correspondence should be addressed: Danielle Samar Peet, University of Newcastle upon Tyne, 143 Marple Road, Offerton, Stockport, Cheshire UK SK2 5EP. tel: 07734949147

E-mail: d.s.peet@ncl.ac.uk brain lesion. CP can manifest itself in many ways, causing spastic, dyskinetic, dystonic, ataxic and mixed palsies. The prevalence of CP is $2-2.5$ of every 1000 live-born children in the Western world, making it one of the most common causes of motor disability in children. CP is associated with low birth weight and gestational age $(2,3,4)$. CP has important comorbidities, 
such as visual impairments, learning difficulties and epilepsy (5).

Epilepsy is one of the most common neuroimpairments in childhood, with a prevalence of 5 - 7\% in the general population (5). Although there is some conflict in the literature, it appears that the prevalence of epilepsy in children and adults with $\mathrm{CP}$ is between 15 - 55\% (5). In addition, if learning difficulties and CP coexist, the risk of epilepsy in children with $\mathrm{CP}$ rises to $71 \%$ (5).

Furthermore, Robinson found that $21 \%$ of children with language impairment had seizures (6). These are children who cannot understand or express themselves (either verbally or non-verbally) in the normal way expected of age-matched peers within the general population (6).

Utilizing an audit of clinical notes for children at two schools in one city, this study investigated whether a higher incidence of epilepsy existed in children with $\mathrm{CP}$, learning difficulties (LD) or language and communication difficulties (LACD) compared to children without these conditions. In addition, data was studied to ascertain whether an earlier age of onset, low birth weight or gestational age is associated with increased incidence of $\mathrm{CP}, \mathrm{LD}$ or LACD. Conclusions made from local data could then allow for the possibility of adequate planning of services for these children.

\section{METHODS}

School A and school B are special primary schools in the city of Newcastle upon Tyne, UK. School A enrolls children with a variety of developmental difficulties, whereas pupils at B, a more specialist school, either have CP or LACD. The children are aged between 3 and 13 years old.

Medical records for current pupils in 2004 were obtained and carefully studied over seven weeks (January to February) to collate epidemiological information. Details of the child's birth history, diagnosis (as CP, LACD and/or LD), past history of syndromes, past history of epilepsy, age of onset, presence of neonatal encephalopathy, infantile spasms and febrile convulsions, type of epilepsy, frequency of fits were recorded. Epilepsy was recorded as active if the child was currently on anti-epileptic medication.

Data was analysed using t-tests and $\mathrm{X}^{2}$ tests in Stata v8.0.

\section{RESULTS}

\section{Population characteristics}

Medical records for all 59 of the pupils at School B were obtained and studied. Medical records for 83 (77\% of pupils) at School A were collected. The mean age of children at School A was 7.29 years (s.d. 2.33). The mean age of children at School B was 8.20 years (s.d. 2.48). Children at School B were older $(\mathrm{t}=-2.17, p=$ $0.03)$

Table 1 shows the number of children with each diagnosis by gender. Many children had a combination of diagnoses, therefore totals in each gender row exceed $100 \%$. Epilepsy, both active and inactive, was more common in females than males $\left(X^{2}=9.07, p<0.01\right)$. Although there were more females with $\mathrm{CP}$ and more males with LACD and LD, the differences between groups were not statistically significant. At each school there were three children that had a combination of $\mathrm{CP}$, LD and LACD. There were 62 cases of epilepsy (seizures at any time) in the combined school population, representing $43 \%$ of the total.

Table 1. Prevalence of CP, LD and LACD and epilepsy in schools A and B combined

\begin{tabular}{|c|c|c|c|c|c|}
\hline & $\begin{array}{l}\text { Epilepsy } \\
\text { at any } \\
\text { time } \\
(\mathrm{n} \%)\end{array}$ & $\begin{array}{l}\text { Active } \\
\text { Epilepsy } \\
(\mathbf{n} \%)\end{array}$ & CP & $\begin{array}{l}\text { LACD } \\
(\mathbf{n} \%)\end{array}$ & $\begin{array}{l}\text { LD } \\
(\mathbf{n} \%)\end{array}$ \\
\hline Girls & $\begin{array}{l}36 \\
(57 \%)\end{array}$ & $\begin{array}{l}22 \\
(35 \%)\end{array}$ & $\begin{array}{l}26 \\
(41 \%)\end{array}$ & $\begin{array}{l}25 \\
40(\%)\end{array}$ & $\begin{array}{l}36 \\
(43 \%)\end{array}$ \\
\hline Boys & $\begin{array}{l}26 \\
(32 \%)\end{array}$ & $\begin{array}{l}15 \\
(19 \%)\end{array}$ & $\begin{array}{l}25 \\
(31 \%)\end{array}$ & $\begin{array}{l}42 \\
(52 \%)\end{array}$ & $\begin{array}{l}38 \\
(47 \%)\end{array}$ \\
\hline$x^{2}$ & 9.0655 & 4.4326 & 1.6775 & 2.1094 & 1.48 \\
\hline P Value & $0.003^{* *}$ & $0.035^{* *}$ & 0.195 & 0.146 & 0.223 \\
\hline \multicolumn{6}{|c|}{$\begin{array}{l}\text { CP, Cerebral Palsy; LD, Learning Difficulties; LACD, Learning } \\
\text { and Communication Difficulties. } \\
\text { *represents percentage of all of one sex } \\
* * P<0.5\end{array}$} \\
\hline
\end{tabular}

Table 2 shows the distribution of all five conditions by school. Separate school data shows that more children at school B had CP than school A $\left(\mathrm{X}^{2}=9.56\right.$, $p<0.01)$ or language and communication problems $\left(\mathrm{X}^{2}=4.25, p=0.04\right)$. More children at school A had learning difficulties $\left(\mathrm{X}^{2}=32.41, p<0.01\right)$ or active epilepsy $\left(\mathrm{X}^{2}=3.03, p=0.08\right)$ compared to school B.

\section{Epilepsy combined with other diagnoses}

Table 3 reports the association between active epilepsy or CP, LACD, or LD. The results show that active epilepsy was significantly more common in those children with $\mathrm{CP}$ when compared to children without $\mathrm{CP}\left(\mathrm{X}^{2}=7.58, p=0.01\right)$. There was no association between active epilepsy and the presence of LD However, all children with CP and LD had epilepsy (n $=6$ ). Interestingly, epilepsy was more likely to occur in children without LACD $\left(\mathrm{X}^{2}=8.45, p<0.01\right)$. 
Table 2. Prevalence of CP, LD and LACD and epilepsy in schools A and B seperately

\begin{tabular}{|c|c|c|c|c|c|}
\hline & $\begin{array}{l}\text { Epilepsy } \\
\text { at any } \\
\text { time } \\
(\mathbf{n} \%)\end{array}$ & $\begin{array}{l}\text { Active } \\
\text { Epilepsy } \\
(\mathbf{n} \%)\end{array}$ & $\begin{array}{l}\text { CP } \\
(\mathbf{n} \%)\end{array}$ & $\begin{array}{l}\text { LACD } \\
(\mathbf{n} \%)\end{array}$ & $(\mathrm{n} \%)$ \\
\hline School A & $\begin{array}{l}39 \\
(46 \%)\end{array}$ & $\begin{array}{l}26 \\
(19 \%)\end{array}$ & $\begin{array}{l}21 \\
(41 \%)\end{array}$ & $\begin{array}{l}33 \\
(39 \%)\end{array}$ & $\begin{array}{l}60 \\
(71 \%)\end{array}$ \\
\hline School B & $\begin{array}{l}23 \\
(38 \%)\end{array}$ & $\begin{array}{l}11 \\
(19 \%)\end{array}$ & $\begin{array}{l}30 \\
(59 \%)\end{array}$ & $\begin{array}{l}34 \\
(57 \%)\end{array}$ & $\begin{array}{l}14 \\
(23 \%)\end{array}$ \\
\hline$x^{2}$ & 9.355 & 3.0252 & 9.5636 & 4.2499 & 32.4091 \\
\hline P Value & 0.333 & 0.082 & $0.002 * *$ & $0.039 * *$ & $0.000 * *$ \\
\hline \multicolumn{6}{|c|}{$\begin{array}{l}\text { CP, Cerebral Palsy; LD, Learning Difficulties; LACD, Learning } \\
\text { and Communication Difficulties. } \\
\text { *represents percentage of all children at one school } \\
* * \mathbf{P}<0.5\end{array}$} \\
\hline
\end{tabular}

\section{Age of onset}

Using combined data from both schools, females had an earlier age of onset of epilepsy than males $(\mathrm{t}=-2.27$, $p=0.03$, data not shown). The average age of onset in children with CP was earlier at 21.50 months compared to 37.15 in children without $\mathrm{CP}$, although this was not statistically significant $(\mathrm{t}=1.40, p=0.17)$. There was no difference in age of onset of epilepsy in those with or without LACD $(\mathrm{t}=-0.51, p=0.62)$ or $\mathrm{LD}(\mathrm{t}=0.10, p$ $=0.92$ ). Although not statistically significant, the data also showed a trend that those children who developed epilepsy within the first 24 hours of life were more likely to have $\mathrm{CP}$ than those who developed epilepsy later in life $\left(\mathrm{X}^{2}=3.10, p=0.08\right)$. Finally, children with neonatal encephalopathy are more likely to have $\mathrm{CP}$ than those without neonatal encephalopathy $\left(\mathrm{X}^{2}=8.74\right.$, $p<0.01$, data not shown).

\section{Gestational age (GA) and birth weight (BW)}

Table 4 shows the mean gestational age and birth weight in children with CP, LACD, and LD. The results showed that those with $\mathrm{CP}$ tended to have a lower birth weight $(\mathrm{t}=3.15, p<0.01)$ and a shorter gestation $(\mathrm{t}=$ $3.17, p<0.01)$ than children without CP. Although not statistically significant, children with LACD tended to be heavier at birth than children without LACD $(\mathrm{t}=-$ $1.79, p=0.08)$. Those with learning difficulties have a longer gestation compared to those without $(\mathrm{t}=-2.00, p$ $=0.047$ )

There were three anomalous results for birth weight and gestation age. These results, although collected from the notes, seemed unlikely to be correct therefore were excluded from the analysis (see Discussion for details).

\section{DISCUSSION}

The data from the schools shows that the percentage of children with epilepsy was high compared with the general population ( $43 \%$ compared to $7 \%)$. The

Table 3. Association between epilepsy and other diagnoses in schools $\mathrm{A}$ and $\mathrm{B}$ combined

\begin{tabular}{lllll}
\hline & & Active Epilepsy & $\mathbf{X}^{2}$ & P Value \\
\hline CP & Y & $20(40 \% *)$ & 7.5773 & $0.006^{* *}$ \\
& N & $17(19 \%)$ & & \\
\multirow{2}{*}{ LACD } & Y & $10(15 \%)$ & 8.4456 & $0.004^{* *}$ \\
& N & $27(36 \%)$ & & \\
& & & & \\
LD & Y & $18(25 \%)$ & 0.1171 & 0.732 \\
& N & $19(28 \%)$ & & \\
\hline
\end{tabular}

CP, Cerebral Palsy; LD, Learning Difficulties; LACD, Learning and Communication Difficulties.

*represents percentage of all children with $(\mathrm{Y})$ or without $(\mathrm{N})$ a diagnosis

** $\mathbf{P}<0.5$

Table 4. Mean GA and BW in children with CP, LACD and LD

\begin{tabular}{|c|c|c|c|c|c|c|c|c|}
\hline & $\begin{array}{l}\text { Mean } \\
\text { GA } \\
\text { (weeks) }\end{array}$ & S.D & $\mathbf{P}$ & T-S & $\begin{array}{l}\text { Mean } \\
\text { BW } \\
(\mathrm{kg})\end{array}$ & S.D & $\mathbf{P}$ & T-S \\
\hline \multicolumn{9}{|l|}{$\mathrm{CP}$} \\
\hline $\mathrm{Y}$ & 36.23 & 4.99 & $0.002 * *$ & 3.17 & 3.00 & 0.68 & $0.002 * *$ & 3.15 \\
\hline $\mathrm{N}$ & 38.90 & 3.54 & & & 2.46 & 0.94 & & \\
\hline \multicolumn{9}{|c|}{ LACD } \\
\hline $\mathrm{Y}$ & 37.80 & 4.07 & 0.913 & -0.11 & 2.94 & 0.82 & 0.077 & -1.79 \\
\hline $\mathrm{N}$ & 37.70 & 4.70 & & & 2.62 & 0.85 & & \\
\hline \multicolumn{9}{|l|}{ LD } \\
\hline $\mathrm{Y}$ & 38.64 & 3.89 & $0.047 * *$ & -2.00 & 2.81 & 0.77 & 0.327 & -0.99 \\
\hline $\mathrm{N}$ & 36.94 & 4.70 & & & 2.64 & 1.02 & & \\
\hline \multicolumn{9}{|c|}{$\begin{array}{l}\text { CP, Cerebral Palsy; LD, Learning Difficulties; LACD, Learning } \\
\text { and Communication Difficulties; T-S, T-Statistic. } \\
\text { *represents percentage of children with }(\mathrm{Y}) \text { or without }(\mathrm{N}) \text { a } \\
\text { diagnosis } \\
* * \mathbf{P}<0.5\end{array}$} \\
\hline
\end{tabular}

differences between the two schools can be explained by the pupil intake. School A takes children with multiple and more complex disabilities, illustrated by the tendency of more children to have active epilepsy and learning difficulties at this school. School B takes children with CP or LACD, also shown by the data, and is therefore considered more specialised.

The data demonstrates that $40 \%$ of children with CP alone and $100 \%$ of children with a combined diagnosis of CP and LD also had epilepsy $\left(\mathrm{X}^{2}=4.44, p=0.035\right)$. This is comparable with the literature, in which epilepsy occurs in $15-55 \%$ of children and adults with CP alone, rising to $71 \%$ in children also suffering from LD $(5,7-$ 
10). This suggests that epilepsy complicates the medical management of children with existing cognitive disabilities. The proportion of children with epilepsy and LACD (14\%) was comparable to that of the literature $(21 \%)$, and is greater than that of the general population (6). We found that epilepsy occured more in children without LACD, but this may be due to the fact that these children suffered from other, predisposing conditions.

The average age of onset of 21.5 months in children with CP was higher when compared to children without CP. Furthermore, this age of onset was greater than data in the literature [18.9 months (10)]. We also found that children who developed epilepsy within the first 24 hours of life were more likely to develop CP than those with a later onset $(\mathrm{p}=0.08)$, a fact supported by existing literature (7). Finally, we found that neonatal encephalopathy, characterised by disturbed neurological function including seizure activity occurring in the first days of life $(7,11)$, was associated with CP $(p<0.01)$.

The BW and GA of children with $\mathrm{CP}$ from both schools was lower when compared to children without CP $(p<0.01)$, supporting theories that the etiology of $\mathrm{CP}$ is due to prenatal events $(2,7)$. This data also supports conclusions made by an epidemiological study of CP performed in the North East of England from 1964 to 1993 (3). This study concluded that there was a substantial increase in the overall rate of CP over time, caused by increased rate of $\mathrm{CP}$ in those children born weighing less than $2.5 \mathrm{~kg}$. It is conceivable that many children with CP who would have died in the past could now survive because of improvements in the perinatal care of premature and low birth weight babies.

\section{LIMITATIONS}

The small study cohort (only 37 children had active epilepsy) is a considerable limitation and it cannot be determined whether the schools studied were representative of special schools as a whole.

Many of the medical records for pupils in school A were inaccessible due to the amalgamation of hospital files across three different sites. This issue limited data collection, and as a result, also limits potential conclusions that could be drawn. Three pupils were left out of the analysis of BW and GA due to improbable data - two were noted to be above $4 \mathrm{~kg}$ at birth, likely reflecting an older weight, and one recording was illegible. In addition, the lack of documentation of certain details such as association with family history, type of epilepsy and frequency of seizure activity meant that this information could not be included in formal analyses. In addition, definite negatives, such as the absence of seizure activity and family history, are rarely recorded in medical records.

The results are at risk of type two error, which indicates that statistical significance could have been found by chance. This is possible due to the fact that there was no hypothesis stated prior to the beginning of the study, and also to the fact that the the data was collected by 'data dredge' and analysed looking for statistically significant results (12).

This study could be improved by carrying out a prospective study using questionnaires and consultations thereby directly asking patients and their families about their medical history. In addition, investigations such as EEG, video recording and CT could give useful information about the type of epilepsy and its underlying pathology. Standardised scores for LD versus the relatively crude manner in which data was documented would refine the methodology in a future study. Furthermore, the use of a comparison group would strengthen any conclusions made. The comparison group could be children with epilepsy and no $\mathrm{CP}$ at a mainstream school, or a random sample taken from the general population.

It would be interesting to broaden the study questions to include a detailed look at the type and the severity of $\mathrm{CP}$, as some studies have found that epilepsy occurs in a higher rate in certain types of CP (7). In addition, it would be of benefit to look at behaviour and educational attainment in children with epilepsy and CP as opposed to no epilepsy and $\mathrm{CP}$.

\section{CONCLUSION}

The data in this study builds on conclusions made by existing studies, reinforcing the fact that epilepsy commonly accompanies CP. The association between low BW and GA, and early age of onset of seizures in children with $\mathrm{CP}$, illustrates the importance of past medical history from birth to determine any risk factors for epilepsy in later life. Diagnosis and treatment of these children require skills in addition to those needed for non-complicated CP. Therefore, members of the multidisciplinary team managing children in special schools like A and B need to be aware of this association and be educated to adequately manage these children.

\section{ACKNOWLEDGEMENTS}

The author would like to express thanks to Dr. Gibson who both supervised the research project and provided invaluable advice and information., as well as Dr. Drummond and her secratorial staff who helped with data collection. Finally, the author is extremely grateful to Dr. Adams for help with statistical analyses.

\section{REFERENCES}

1. Rosenbaum, P., Cerebral palsy: what parents and doctors want to know. BMJ 2003; 326: 960-974. 
2. Wojciech KU et al. Risk factors and prognosis of epilepsy in children with cerebral palsy in North-Eastern Poland. Brain and Development 2003; 25(7): 499-506.

3. Colver, A. Gibson, $\mathrm{M}$ et al Increasing rates of Cerebral Palsy across the severity spectrum in north-east England 1964-1993. Archives of Disease in Childhood 2000; 83(1): 7-125.

4. 5. Jarvis, S. Studies of the relationship between cerebral palsy and intrauterine growth. Lancet 2003; 362: 1106-11.

5. Wallace, S., Epilepsy in cerebral palsy. Developmental Medicine and Child Neurology 2001; 43: 713-717.

6. Parkinson, G. High incidence of language disorder in children with focal epilepsies. Developmental Medicine and Child Neurology 2002; 44: 533-537.
7. Bruck, I. Et al. Epilepsy in children with cerebral palsy. Arq Neuro-psiquitr 2001; 59(1).

8. Gururaj, AK et al. Epilepsy in children with cerebral palsy. Seizure 2003; 12(2): 110-4.

9. Al-Sulaiman AA., Epilepsy in Saudi children with Cerebral Palsy. Saudi Medical Journal 2001; 22(1): 19-21.

10. Singhi P, et al. Epilepsy in children with Cerebral Palsy. Journal of Child Neurology 2003; 18(3): 174-9.

11. Adamson, $\mathrm{S}$ et al. Predictors of neonatal encephalopathy in full term infants. BMJ 1995; 311: 598-602.

12. Mapleson, W. Why $5 \%$ risk of type- 1 error but $20 \%$ risk of type2 error? Anaethesia, 2004; 59(4): 409.

Danielle Peet graduated with a Bachelor's Degree of Medicine and Surgery from Newcastle University in the UK. She has a special interest in cerebral palsy and other chronic disabilities affecting children. She has spent a considerable amount of time in special schools in the north east of the UK looking at the care of these children from a multidisciplinary team viewpoint. 